\title{
Inhibition of Human Platelet Aggregation by
}

\section{Monovalent Antifibrinogen Antibody Fragments}

\author{
Douglas M. Tollefsen and Philip W. Majerus \\ From the Divisions of Hematology and Oncology, Departments of Internal \\ Medicine and Biochemistry, Washington University School of Medicine, \\ St. Louis, Missouri 63110
}

\begin{abstract}
A B S T R A C T Monovalent goat antibody fragments (Fab) that were monospecific for human fibrinogen were isolated by affinity chromatography on fibrinogenSepharose and used as a direct probe for the involvement of fibrinogen in platelet aggregation and the release reaction. The antifibrinogen Fab inhibited aggregation of washed human platelets induced by thrombin $(0.1-10 \mathrm{U} / \mathrm{ml})$ by $50-95 \%$, but had no effect on $\left[{ }^{14} \mathrm{C}\right]-$ serotonin release and only a slight inhibitory effect on ${ }^{125}$ I-thrombin binding to platelets. Inhibition of aggregation was not observed with nonimmune goat Fab or rabbit antihuman albumin Fab. About 40,000 ${ }^{125} \mathrm{I}$-labeled antifibrinogen Fab molecules per platelet were bound tightly at saturation to surface fibrinogen molecules. After washing the platelets once to remove unbound Fab, aggregation by subsequently added thrombin was no longer inhibited. The antifibrinogen $\mathrm{Fab}$ inhibited the clotting of fibrinogen by thrombin but did not affect the rate of fibrinopeptide $A$ release, indicating that the Fab inhibits clotting by interfering with the polymerization of fibrin monomers. Our experiments suggest that fibrinogen released from platelets is directly involved in thrombin-induced aggregation of washed platelets, perhaps through polymerization of fibrin monomers generated by proteolytic cleavage of released fibrinogen.
\end{abstract}

\section{INTRODUCTION}

Thrombin initiates a series of rapid events in suspensions of washed human platelets. Within seconds after exposure to thrombin, platelets secrete calcium, sero-

A preliminary report of this work was presented at the 17th Annual Meeting of the American Society of Hematology, Atlanta, Ga., 9 December 1974.

Mr. Tollefsen is the recipient of U. S. Public Health Service Medical Scientist Training Program Award GM 02016.

Received for publication 3 December 1974 and in revised form 10 February 1975. tonin, adenine nucleotides, and other substances (a process termed the "release reaction", reference 1), and undergo a change in shape from flattened disks to spheres with many pseudopods (2). Aggregation of the platelets occurs somewhat more slowly but is complete within several minutes. Thrombin induces these reactions at low concentrations of $1 \mathrm{nM}(0.1 \mathrm{U} / \mathrm{ml})$ or less, suggesting that thrombin may be an important mediator of platelet function in hemostasis and thrombosis (3).

Recently, several aspects of the mechanism by which thrombin initiates these events have been elucidated. Thrombin binds reversibly and with high affinity to about 50,000 receptors on the platelet surface (4), which suggests that the plasma membrane is the primary site of action of thrombin. Thrombin treatment of intact platelets causes a rapid decrease in adenylate cyclase activity (5) and a concomitant increase in phosphorylation of a specific protein of molecular weight 40,000 (6). Agents that presumably raise the intracellular concentration of cyclic adenosine $3^{\prime}, 5^{\prime}$ monophosphate inhibit both the phosphorylation induced by thrombin and the release reaction $(6,7)$, suggesting a possible relationship between these processes. A number of alterations in membrane components after thrombin treatment are indicated by changes in the pattern of proteins iodinated with lactoperoxidase (8) and in the number and distribution of lectin-binding sites $(9,10)$, but the importance of these phenomena in aggregation and release is unclear. Thrombin inactivated with diisopropyl fluorophosphate is unable to induce release or aggregation (11) even though this derivative binds to platelets in the same manner as native thrombin (4), indicating that proteolytic activity of thrombin is essential. Although several proteins isolated from platelets, including fibrinogen (12), Factor XIII (13), and thrombosthenin M (14), have peptide

The Journal of Clinical Investigation Volume 55 June 1975·1259-1268

1259 


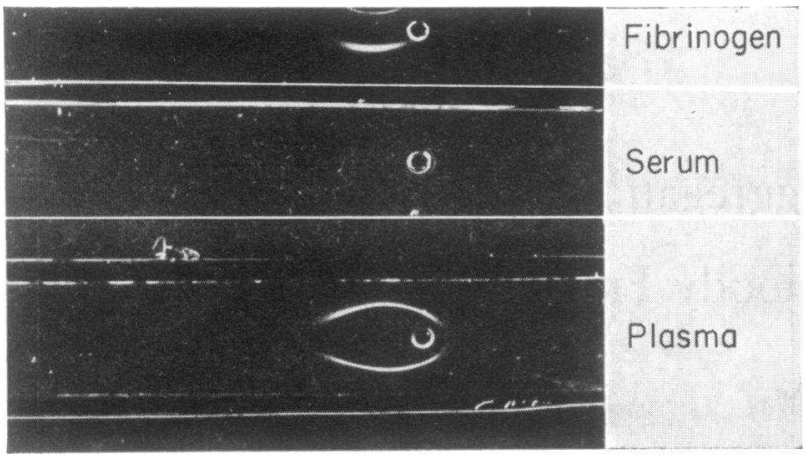

FIGURE 1 Immunoelectrophoresis of human fibrinogen, serum, and plasma vs. goat antihuman fibrinogen antiserum. Antiserum was placed in the longitudinal troughs after electrophoresis, and the precipitates were allowed to form overnight at room temperature.

bonds susceptible to hydrolysis by thrombin, none of these has been shown to be hydrolyzed in intact platelets during release or aggregation.

Several investigators have proposed that platelet fibrinogen is the substrate for thrombin and that "polymerizing fibrin" plays a central role in aggregation (15-17), but evidence to the contrary has also been reported $(11,18-20)$. In addition, numerous laboratories have shown that added fibrinogen is required for ADP-induced aggregation but not for thrombin-induced aggregation (21-23). This has led previous workers to postulate that thrombin-induced aggregation might be mediated by platelet fibrinogen. In our current investigation we have tested the hypothesis that platelet fibrinogen is involved in release and aggregation and that it might be a receptor for thrombin binding. To do this we prepared antibody fragments (Fab) that bind specifically to human fibrinogen and inhibit the polymerization of fibrin monomers, and we determined their effect on washed human platelets exposed to thrombin. Thrombin-induced aggregation was markedly inhibited by the Fab fragments, while $\left[{ }^{14} \mathrm{C}\right]$ serotonin release was unaffected. Binding of ${ }^{125} \mathrm{I}$-thrombin was inhibited to a small extent. These experiments provide direct evidence that platelet fibrinogen is involved in aggregation of washed platelets.

\section{METHODS}

Materials. Human fibrinogen was purified from plasma by the method of Straughn and Wagner (24); this preparation contained $95 \%$ clottable protein. Fibrinogen concentrations were calculated from the absorbance at $280 \mathrm{~nm}$, assuming $E_{280}{ }^{1 \%}=16.2(25)$. Bovine thrombin $(2,300 \mathrm{U} / \mathrm{mg})$ was purified and assayed as previously described (4). Cyanogen bromide was purchased from Eastman Organic Chemicals Div., Eastman Kodak Co. (Rochester, N. Y.); imidazole (grade III, low fluorescence blank) was obtained from Sigma Chemical Co. (St. Louis, Mo.) ; and fluorescamine was purchased from Pierce Chemical Co. (Rockford,
I11.). Concentrations of proteins other than fibrinogen and thrombin were determined by ultraviolet absorption, assuming $E_{280}{ }^{1 \%}=10.0$

Preparation of platelets. Platelets were isolated from human blood and washed as previously described (4). All experiments were performed with platelets suspended in isotonic Tris-saline $(0.0154 \mathrm{M}$ Tris- $\mathrm{HCl}, 0.14 \mathrm{M} \mathrm{NaCl})$ $\mathrm{pH} 7.5$, containing glucose $(1 \mathrm{mg} / \mathrm{ml})$. Platelets used in serotonin release experiments were incubated with $\left[{ }^{14} \mathrm{C}\right]-$ serotonin before washing, and serotonin release was measured as described previously (4).

Preparation of human fibrinogen-Sepharose. Sepharose 4B ( $100 \mathrm{ml}$ settled volume) was activated by the procedure of Cuatrecasas (26) using $23 \mathrm{~g}$ of cyanogen bromide. The activated Sepharose was washed quickly on a Buchner funnel with cold isotonic Tris-saline $(\mathrm{pH} 7.5)$ and added to $740 \mathrm{mg}$ of human fibrinogen in $100 \mathrm{ml}$ of this buffer. The mixture was stirred overnight at $4^{\circ} \mathrm{C}$, and the beads were washed successively with 2 liters each of $0.1 \mathrm{M}$ sodium carbonate $(\mathrm{pH}$ 9.7), $0.1 \mathrm{M}$ glycine- $\mathrm{HCl}(\mathrm{pH} 2.2)$, and isotonic Tris-saline ( $\mathrm{pH} 7.5)$. The coupling efficiency was $87 \%$, yielding $6.4 \mathrm{mg}$ of fibrinogen covalently bound $/ \mathrm{ml}$ of Sepharose. The fibrinogen-Sepharose was stored at $4^{\circ} \mathrm{C}$ in isotonic Tris-saline containing $0.2 \mathrm{mg} / \mathrm{ml}$ sodium azide and was washed as above immediately before use to remove any fibrinogen hydrolyzed during storage. A single preparation was used repeatedly over a period of several months.

Purification of antifibrinogen antibody. Antiserum prepared from a goat immunized against human fibrinogen was purchased from Gateway Immunosera, Cahokia, Ill. This antiserum precipitated a single component of human plasma that corresponded to purified human fibrinogen as determined by immunoelectrophoresis (Fig. 1). The antiserum $(45 \mathrm{ml})$ was adjusted to contain $4 \mathrm{mM}$ diisopropyl fluorophosphate, and after $30 \mathrm{~min}$ at room temperature, the solution was applied to a column containing $95 \mathrm{ml}$ of human fibrinogen-Sepharose. The column was washed at room temperature with isotonic Tris-saline $(\mathrm{pH} 7.5)$ until the $A_{280}$ of the effluent was less than 0.040 . The column was then eluted in sequence with the following buffers: $0.1 \mathrm{M}$ sodium carbonate $(\mathrm{pH} 9.7) ; 1.0 \mathrm{M}$ sodium chloride buffered with $0.015 \mathrm{M}$ Tris- $\mathrm{HCl}(\mathrm{pH} 7.4)$; and $0.1 \mathrm{M}$ glycine$\mathrm{HCl}(\mathrm{pH} 2.2)$. Fractions of each eluate with $A_{280}$ greater than 0.500 were combined and dialyzed against isotonic Tris-saline at $4^{\circ} \mathrm{C}$. The eluates were sometimes concentrated by ultrafiltration using an Amicon UM-10 membrane (Amicon Corp., Scientific Systems Div., Lexington, Mass.). The eluates were stored at $4^{\circ} \mathrm{C}$ and were characterized further as described in Results.

Preparation of antifibrinogen Fab fragments. Antifibrinogen antibody ( $\mathrm{pH} 2.2$ eluate from fibrinogen-Sepharose; see Results) was dialyzed against $0.1 \mathrm{M}$ sodium phosphate ( $\mathrm{pH}$ 6.1). After dialysis this solution contained $98 \mathrm{mg}$ of antibody in $37.5 \mathrm{ml}$ of buffer. The antibody was hydrolyzed by addition of $0.4 \mathrm{ml}$ of $0.25 \mathrm{M} \mathrm{Na} 2 \mathrm{EDTA}(\mathrm{pH} 7), 0.8 \mathrm{ml}$ of $0.5 \mathrm{M}$ cysteine, and $0.035 \mathrm{ml}$ of Sigma twice crystallized papain $(30 \mathrm{mg} / \mathrm{ml}$ suspension in sodium acetate). After an 18 -h incubation at $37^{\circ} \mathrm{C}$ under an atmosphere of toluene, the papain was inactivated by the addition of $4.0 \mathrm{ml}$ of $N$-ethylmaleimide $(25 \mathrm{mg} / \mathrm{ml})$. The digest was dialyzed extensively against isotonic Tris-saline at $4^{\circ} \mathrm{C}$, and the precipitate that formed was removed by centrifugation. The recovery of soluble protein after this step was $67 \mathrm{mg}$. The digest was then applied to a column containing $80 \mathrm{ml}$ of fibrinogen-Sepharose, and the column was washed with isotonic Tris-saline to elute the Fc fragments. The Fab fragments were eluted with $0.1 \mathrm{M}$ glycine- $\mathrm{HCl}(\mathrm{pH} 2.2)$, 
dialyzed against isotonic Tris-saline $\left(\mathrm{pH} \mathrm{7.5)}\right.$ at $4^{\circ} \mathrm{C}$, and stored at $4^{\circ} \mathrm{C}$ after being concentrated to about $10 \mathrm{mg} / \mathrm{ml}$ by ultrafiltration. The total recovery of protein in the Fab fraction was $37 \mathrm{mg}$.

Precipitin reaction. Quantitative precipitin reactions were carried out according to standard procedures (27). ${ }^{125}$ I-Fibrinogen (95\% clottable after iodination) was used to quantitate the precipitated fibrinogen.

Preparation of control goat $I g G$, rabbit antihuman albumin $I g G$, and Fab fragments. Nonimmune goat serum and rabbit antihuman albumin antiserum were purchased from Gateway Immunosera. Each serum $(10 \mathrm{ml})$ was dialyzed against $0.1 \mathrm{M}$ potassium phosphate $(\mathrm{pH} 8)$ and applied to a $50-\mathrm{ml}$ column of DEAE-cellulose equilibrated with this buffer. The columns were eluted with this buffer, and the purified IgG fractions were obtained in the unretained eluate. About $1 \mathrm{mg}$ of human albumin was precipitated per $\mathrm{mg}$ of IgG prepared from the antialbumin antiserum. Papain digestions were carried out as described in the preceding section.

Measurement of antifibrinogen Fab binding to platelets. Fab fragments were iodinated, and binding studies were carried out as described previously for phytohemagglutinin (28).

Platclet aggregation studies. Aggregation was measured photometrically by the method of Born (29) in a Payton dual-channel aggregometer. Platelet suspensions $(0.45 \mathrm{ml}$; $5 \times 10^{8}$ platelets $/ \mathrm{ml}$ in isotonic Tris-saline containing $2 \mathrm{mM}$ $\mathrm{CaCl}_{2}$ ) were warmed to $37^{\circ} \mathrm{C}$ in siliconized glass cuvettes and stirred at $1,100 \mathrm{rpm}$ in the aggregometer. Additional substances were added totaling $0.05 \mathrm{ml}$. The recorder was adjusted to read $0 \%$ with a cuvette containing the starting platelet suspension and $100 \%$ with a cuvette containing buffer only.

Measurcment of thrombin binding to platclets. Bovine thrombin was labeled with ${ }^{125} \mathrm{I}$, and binding studies were carried out as described in a previcus report (4). "Nonspecific" binding of ${ }^{125}$ I-thrombin, which represented less than $25 \%$ of the total thrombin bound, was determined in incubations containing an excess of unlabeled thrombin and was a linear function of the ${ }^{125} \mathrm{I}$-thrombin concentration. Binding data are presented in Fig. 5 after subtraction of nonspecific binding.

Mcasurement of fibrinopeptides. Fibrinogen was dissolved in water and chromatographed on Sephadex G-150 equilibrated with $0.154 \mathrm{M}$ sodium chloride, $0.01 \mathrm{M}$ imidazole- $\mathrm{HCl}(\mathrm{pH} \mathrm{7.0)}$. This procedure removed low molecular weight material that contributed to the fluorescence background of the assay. Reaction mixtures contained $150 \mu \mathrm{g} / \mathrm{ml}$ of fibrinogen, $0.02 \mathrm{M}$ calcium chloride, and $1 \mathrm{U} / \mathrm{ml}$ of thrombin (added last to initiate the reaction) in $0.5 \mathrm{ml}$ of the above buffer. The reaction was allowed to proceed at room temperature and was terminated by the addition of $0.05 \mathrm{ml}$ of $100 \%$ trichloroacetic acid (TCA). The mixture was placed on ice, and the precipitate that formed was removed by centrifugation. An aliquot of the supernate $(0.45 \mathrm{ml})$ was mixed with an equal volume of $0.4 \mathrm{M}$ sodium phosphate $(\mathrm{pH} 8)$ containing $0.556 \mathrm{M}$ sodium hydroxide to neutralize the TCA. Calcium phosphate precipitated and was removed by centrifugation. A $0.8-\mathrm{ml}$ aliquot of the supernate, which contained the fibrinopeptides, was mixed rapidly with $0.2 \mathrm{ml}$ of fluorescamine $(3 \mathrm{mg} / \mathrm{ml}$ in acetone) on a Vortex mixer at room temperature (Scientific Industries, Inc., Queens Village, N. Y.) (30). Relative fluorescence was measured in a Farrand A-4 fluorometer (Farrand Optical Co., Inc., Valhalla, N. Y.). The blank was a sample processed in an identical manner except that thrombin was omitted from the reaction.

To establish that fibrinopeptide $\mathrm{A}$ was measured by this procedure, a portion of the TCA supernate from a 2-min incubation with thrombin was subjected to paper electrophoresis as described by Herzig, Ratnoff, and Shainoff (31). Duplicate electropherograms were stained for arginine (32) and for amino groups (by dipping the paper in $3 \mathrm{mg} / \mathrm{ml}$ fluorescamine in acetone). A single spot migrating as fibrinopeptide A was detected by both stains.

\section{RESULTS}

Purification of antihuman fibrinogen antibody. To test the effects of antibodies to fibrinogen on the reaction of thrombin with platelets, it was necessary to separate the antibodies from serum proteins that inhibit thrombin. Goat antiserum $(45 \mathrm{ml})$ was chromatographed on a column of human fibrinogen-Sepharose as described in Methods (Fig. 2). The affinity column was eluted first with $0.1 \mathrm{M}$ sodium carbonate $(\mathrm{pH}$ 9.7). This eluate contained $39.7 \mathrm{mg}$ of protein, and after dialysis against isotonic Tris-saline $(\mathrm{pH} 7.5)$, it precipitated $0.9 \mathrm{mg}$ of ${ }^{125} \mathrm{I}$-human fibrinogen $/ \mathrm{mg}$ of eluted protein at the equivalence point of a quantitative precipitin curve. Although antibody was present, this eluate contained several contaminating proteins demonstrated by polyacrylamide gel electrophoresis in sodium dodecyl sulfate and was therefore discarded. The second eluate, obtained with $1.0 \mathrm{M}$ sodium chloride, 0.015 $\mathrm{M}$ Tris- $\mathrm{HCl}(\mathrm{pH} 7.4)$, did not contain any detectable protein. The final elution with $0.1 \mathrm{M}$ glycine- $\mathrm{HCl}(\mathrm{pH}$ 2.2) removed $198 \mathrm{mg}$ of protein that was homogeneous by sodium dodecyl sulfate gel electrophoresis run in the absence of reducing agents and had a mobility on standard immunoelectrophoresis similar to that of control

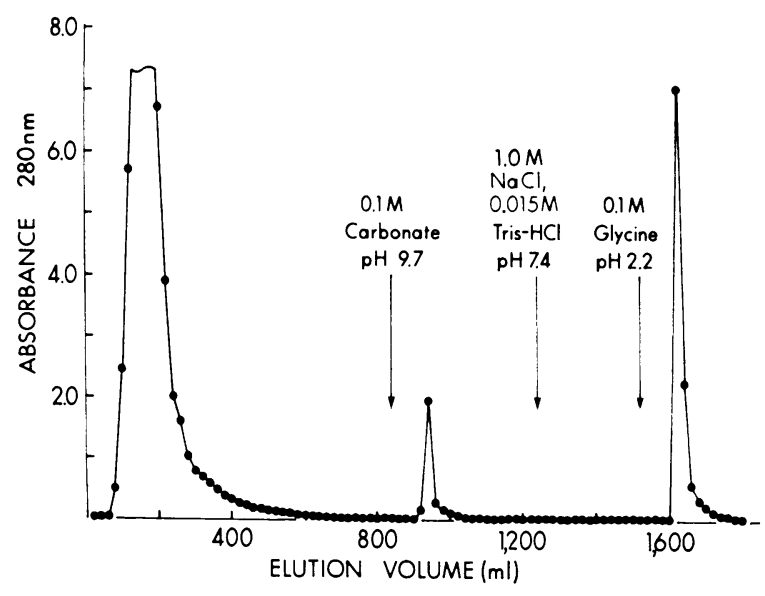

FigLre 2 Affinity chromatography of goat antifibrinogen antiserum. Antiserum $(45 \mathrm{ml})$ was treated with diisopropyl fluorophosphate as described in Methods and applied to a 95-ml column of human fibrinogen-Sepharose equilibrated with isotonic Tris-saline $(\mathrm{pH} \mathrm{7.5)}$. The column was washed with this buffer and eluted as shown.

Inhibition of Platelet Aggregation 


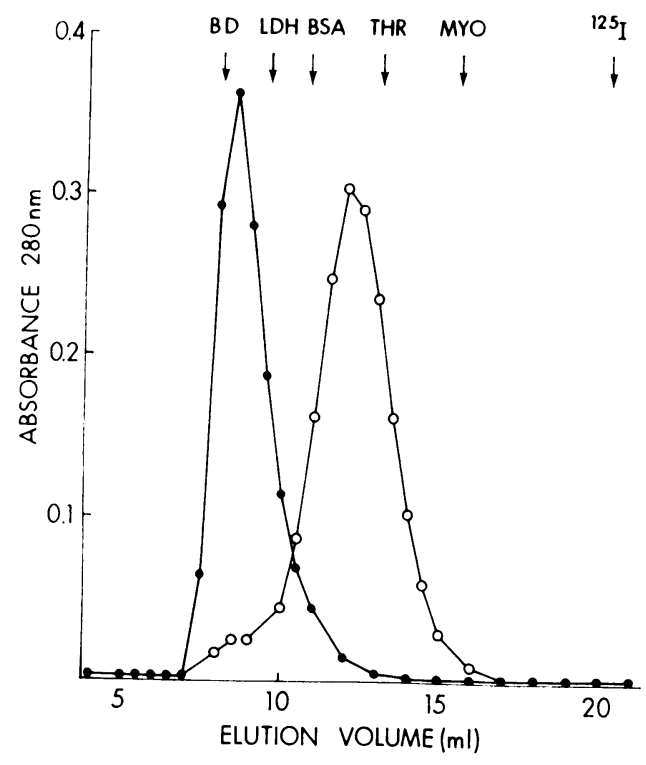

Figure 3 Chromatography of antifibrinogen antibody and Fab fragments on Sephadex G-150. Samples containing about $1 \mathrm{mg}$ of protein in $0.5 \mathrm{ml}$ were applied to a $0.9 \times 28-$ cm column of Sephadex G-150 and eluted with isotonic Trissaline $(\mathrm{pH} 7.5)$. The void volume and included volume were determined with blue dextran and $\left[{ }^{125} \mathrm{I}\right]$ sodium iodide, respectively. Protein standards and their molecular weights were: rabbit muscle lactate dehydrogenase $(132,000)$; bovine serum albumin $(69,000)$; bovine thrombin $(39,000)$; and sperm whale myoglobin $(17,800)$. ( $)$, antifibrinogen antibody ( $\mathrm{pH} 2.2$ eluate from fibrinogen-Sepharose; see Fig. $2)$. (O), antifibrinogen Fab isolated from papain digest by affinity chromatography.

goat IgG. The dialyzed eluate contained antibodies that precipitated $1.5 \mathrm{mg}$ of ${ }^{125} \mathrm{I}$-fibrinogen $/ \mathrm{mg}$ of eluted protein. No additional protein was eluted from a portion of the fibrinogen-Sepharose by $8 \mathrm{M}$ urea.

Preparation of antifibrinogen Fab fragments. Platelets contain a large amount of fibrinogen, comprising about $10 \%$ of the total platelet protein (33). Fibrinogen located on the exterior surface of washed platelets would constitute a potential substrate in the initial thrombin-platelet interaction. In preliminary experiments using the isolated antifibrinogen antibodies labeled with ${ }^{125} \mathrm{I}$, we determined that the antibodies bound to intact platelets, indicating the presence of platelet surface fibrinogen. Furthermore, these antibodies caused a slow release of $\left[{ }^{14} \mathrm{C}\right]$ serotonin from platelets at concentrations greater than $250 \mu \mathrm{g} / \mathrm{ml}$, which was consistent with previous experiments indicating that antibodies to platelet surface antigens stimulate release (34). In an attempt to produce a probe for fibrinogen that would not stimulate release, we prepared monovalent $\mathrm{Fab}$ fragments from the purified antifibrinogen antibody by papain digestion, and the $\mathrm{Fab}$ fragments were isolated from the reaction mixture by affinity chromatography on fibrinogen-Sepharose (see Methods). In contrast to the intact antibody, the Fab fragments no longer induced the release reaction. The protein eluted from fibrinogen-Sepharose was identified as antihuman fibrinogen Fab fragments by the following criteria: (a) The protein had a molecular weight of 48,000 determined by Sephadex G-150 chromatography (Fig. 3) relative to standard proteins (35). (b) The protein was bound completely to fibrinogen-Sepharose but no longer precipitated fibrinogen, although as seen in Fig. 3, approximately $4 \%$ of the protein eluted from Sephadex G-150 in the position of intact antibody. (c) The protein inhibited the precipitation of ${ }^{125}$ I-fibrinogen by intact antihuman fibrinogen antibodies. For example, with a ratio of fibrinogen to intact antibody equal to the equivalence point of the precipitin reaction (see above), a fivefold molar excess of Fab blocked precipitation by $93 \%$.

Binding of antifibrinogen Fab to platelets. The binding of ${ }^{120} \mathrm{I}$-antifibrinogen $\mathrm{Fab}$ to intact platelets was saturable as shown in Fig. 4 (equilibrium of binding was achieved within $5 \mathrm{~min}$ ). Greater than $95 \%$ of the labeled Fab could be displaced by a 50 -fold excess of unlabeled antifibrinogen Fab (not shown), suggesting that the binding was specific. Moreover, nonimmune goat $\mathrm{Fab}$ fragments did not bind to platelets at similar concentrations. Purified human fibrinogen at a 10 -fold greater concentration $(200 \mu \mathrm{g} / \mathrm{ml})$ than the total platelet fibrinogen present in our assay system did not cause ${ }^{125} \mathrm{I}$-antifibrinogen $\mathrm{Fab}$ fragments to bind to Millipore filters (Millipore Corp., Bedford, Mass.), thus excluding the possibility that the observed binding

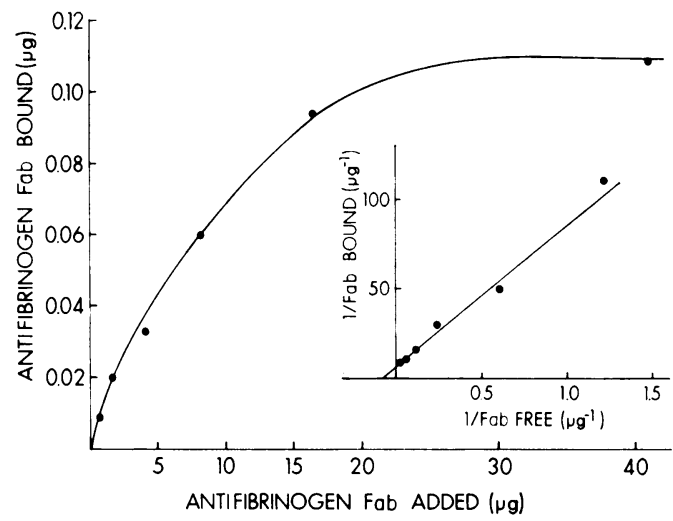

Figure 4 Binding of ${ }^{125}$ I-labeled antifibrinogen $\mathrm{Fab}$ to intact platelets. Each incubation included $0.5 \times 10^{8}$ platelets and the specified amount of $\mathrm{Fab}(32,000 \mathrm{cpm} / \mu \mathrm{g})$ in $0.5 \mathrm{ml}$ of isotonic Tris-saline ( $\mathrm{pH} 7.5$ ). After $30 \mathrm{~min}$ at room temperature the incubations were terminated by Millipore filtration as previously described (28), and the filters were counted. Parallel incubations without platelets were used to determine nonspecific binding of Fab to the filters, and these values were subtracted. 
was due to fibrinogen released from platelets during the 30-min incubation. Multiple additional washes of the platelets before incubation with the labeled antifibrinogen Fab did not result in appreciably less Fab bound, indicating that the surface fibrinogen molecules are associated tightly with the platelet.

The amount of antifibrinogen Fab bound at saturation was calculated (36) from the intercept on the ordinate of a double reciprocal plot of the binding data (Fig. 4 inset); this value was $0.34 \mu \mathrm{g} / 10^{8}$ platelets. If we assume uniform labeling of the Fab fragments and a molecular weight of 48,000 , we can estimate that about 40,000 Fab fragments were bound to each platelet at saturation. Since we have no information concerning the stoichiometry of binding of the Fab to platelet surface fibrinogen, it is impossible to calculate the number of surface fibrinogen molecules corresponding to the Fab molecules bound. The maximum, however, would be 40,000 surface fibrinogen molecules per platelet (or about $10 \%$ of the total platelet fibrinogen) if each fibrinogen binds only one Fab molecule. It is likely that the amount of surface fibrinogen is in fact less than this. In other experiments we demonstrated that all of the ${ }^{125} \mathrm{I}-\mathrm{Fab}$ could bind to platelets when repeated additions of platelets to Fab were performed. This suggests that all of the antigenic determinants of plasma fibrinogen are present on platelet surface fibrinogen and available to antibody and that the observed binding was not due to a minor population of Fab molecules directed toward an antigen other than fibrinogen.

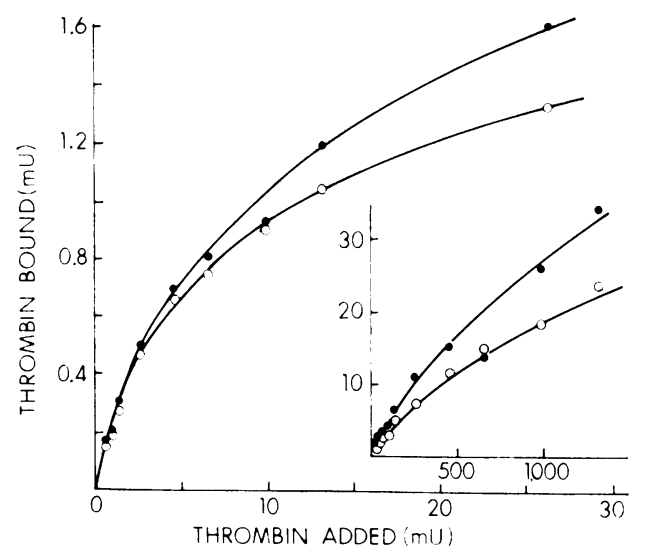

FigUre 5 Effect of antifibrinogen $\mathrm{Fab}$ on binding of ${ }^{125} \mathrm{I}$ thrombin to platelets. Each incubation included $0.5 \times 10^{5}$ platelets and the specified amount of thrombin $(1,800 \mathrm{cpm} /$ $\mathrm{mU})$ in $0.5 \mathrm{ml}$ of isotonic Tris-saline $(\mathrm{pH} \mathrm{7.5)}$. 30-min incubations were performed as described previously (4). Nonspecific binding was determined in parallel incubations containing platelets and excess unlabeled thrombin, and the data are presented after subtraction of this nonspecific binding. (๑), no Fab added. (O), $180 \mu \mathrm{g} / \mathrm{ml}$ antifibrinogen Fab added $5 \mathrm{~min}$ before thrombin.

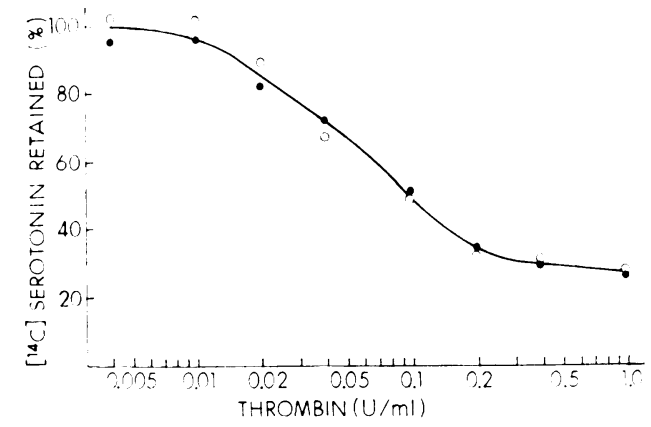

Figure 6 Effect of antifibrinogen $\mathrm{Fab}$ on thrombin-induced release of $\left[{ }^{14} \mathrm{C}\right]$ serotonin from platelets. Platelets were loaded with $\left[{ }^{14} \mathrm{C}\right]$ serotonin as previously described (4). Each incubation included $0.5 \times 10^{8}$ platelets in $0.5 \mathrm{ml}$ of isotonic Tris-saline $(\mathrm{pH} 7.5)$. After a 5-min preincubation with the Fab, thrombin was added at the concentrations indicated to initiate the reaction. After a 10 -min incubation with thrombin, the reaction was terminated by Millipore filtration (4). Release is expressed as the percentage of serotonin retained in the platelets compared to control incubations without thrombin. $(\bullet)$, no Fab added. ( $\bigcirc), 100$ $\mu \mathrm{g} / \mathrm{ml}$ antifibrinogen $\mathrm{Fab}$ added.

Effect of antifibrinogen Fab on ${ }^{125} I$-thrombin binding to platclcts. To determine whether surface fibrinogen serves as a thrombin receptor, we tested the effect of antifibrinogen $\mathrm{Fab}$ on the binding of ${ }^{125} \mathrm{I}$-thrombin to intact platelets. Binding was measured over a wide range of thrombin concentrations $(0.0013$ to $2.6 \mathrm{U} / \mathrm{ml})$ in the presence of the Fab. A saturating concentration of the antifibrinogen $\mathrm{Fab}$ had little effect on thrombin binding up to about $0.02 \mathrm{U} / \mathrm{ml}$ of thrombin (Fig. 5) but inhibited binding by about $30 \%$ at $1 \mathrm{U} / \mathrm{ml}$ (Fig. 5 inset).

From the experiment described above (Fig. 4), we observed that approximately 40,000 antifibrinogen Fab molecules were bound per platelet at saturation with an apparent dissociation constant of $25 \mu \mathrm{g} / \mathrm{ml}$ (determined from the intercept on the abscissa of Fig. 4 inset). If fibrinogen comprised all 50,000 thrombin-binding sites (4), one Fab molecule could bind per thrombin-binding site. Assuming competitive binding between thrombin and the Fab, one would predict an 8.2-fold increase in the apparent dissociation constant for thrombin in the presence of $180 \mu \mathrm{g} / \mathrm{ml}$ of antifibrinogen Fab (the concentration used in Fig. 5). Inhibition of this magnitude was not observed, arguing against this simple hypothesis.

${ }^{1}$ Calculated from the relationship $1 / K_{p}=1 / K_{m}\left(1+i / K_{i}\right)$, where $K_{p}=$ apparent dissociation constant for thrombin binding in the presence of antifibrinogen Fab; $K_{m}=$ apparent dissociation constant for thrombin binding in the absence of the Fab; $K_{i}=$ apparent dissociation constant for antifibrinogen Fab binding; and $i=$ concentration of antifibrinogen Fab. 


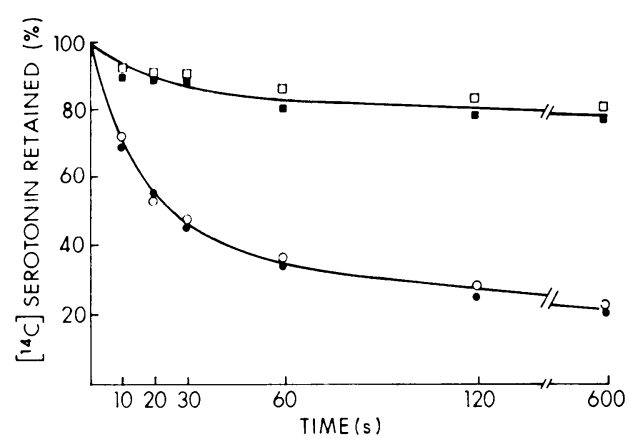

FIGURE 7 Effect of antifibrinogen Fab on thrombin-induced release of $\left[{ }^{14} \mathrm{C}\right]$ serotonin from platelets. Incubations were conducted as in Fig. 6 for varying periods of time after the addition of thrombin. Fab, when present, was added $5 \mathrm{~min}$ before thrombin. ( $\square), 0.02 \mathrm{U} / \mathrm{ml}$ thrombin. ( $\square$ ), 0.02 $\mathrm{U} / \mathrm{ml}$ thrombin $+100 \mu \mathrm{g} / \mathrm{ml}$ antifibrinogen Fab. (•), 0.1 $\mathrm{U} / \mathrm{ml}$ thrombin. (O), $0.1 \mathrm{U} / \mathrm{ml}$ thrombin $+100 \mu \mathrm{g} / \mathrm{ml}$ antifibrinogen Fab.

As we have previously reported (4), the kinetics of thrombin binding are complex in that the affinity of platelets for thrombin decreases as more thrombin is bound. This could be explained either by a negative cooperative interaction among receptor sites of a single kind or by multiple receptor sites with different affinities for thrombin. The inhibition of thrombin binding by antifibrinogen Fab seen at higher thrombin concentrations could reflect a subpopulation of thrombin-binding sites that are, in fact, fibrinogen.

Effect of antifibrinogen $F a b$ on the platelet release reaction. At a concentration of antifibrinogen $\mathrm{Fab}$ that is saturating with respect to surface fibrinogen, the Fab had no effect on either the rate or the extent of $\left[{ }^{14} \mathrm{C}\right]$ serotonin release induced by varying concentrations of thrombin (Figs. 6 and 7). Unlike intact antifibrinogen antibody, the antifibrinogen Fab by itself did not cause release (data not shown).

Effect of antifibrinogen Fab on platelet aggregation. Platelet aggregation was measured by a photometric technique using a platelet aggregometer (see Methods). Thrombin produced the aggregation response shown in Fig. 8A with platelets suspended in isotonic Tris-saline $(\mathrm{pH} 7.5)$ in the presence of $2 \mathrm{mM}$ calcium chloride. The lower limit of thrombin for maximal aggregation in this system was about $0.1 \mathrm{U} / \mathrm{ml}$.

Thrombin-induced aggregation was markedly inhibited by antifibrinogen Fab fragments (Fig. 8B). The degree of inhibition based on the change in optical density produced by exposure to thrombin for $10 \mathrm{~min}$ varied with platelets from different donors. At a fixed concentration of the $\mathrm{Fab}(100 \mu \mathrm{g} / \mathrm{ml}),>90 \%$ inhibition was obtained in two of the six donors and $>50 \%$ inhibition in all six donors. By increasing the Fab concentration, greater inhibition could generally be ob- tained. The inhibition by antifibrinogen Fab could not be overcome by thrombin concentrations as high as $10 \mathrm{U} / \mathrm{ml}$.

As Born has pointed out (37), the aggregometer is relatively insensitive to the formation of small aggregates (up to about 10 platelets each). To determine whether aggregates of this size were forming in the presence of the Fab, platelets were removed from the aggregometer cuvette and examined by phase-contrast microscopy in a hemocytometer. No aggregates were observed among platelets taken from the experiment shown in Fig. 8B (after 15 min of exposure to thrombin in the presence of the antifibrinogen $\mathrm{Fab}$ ) or from other experiments in which a similar degree of inhibition was obtained, and the count of single platelets was not reduced compared with control suspensions. In cases where less inhibition was obtained (four of the six donors), a few large aggregates were observed in fields composed predominantly of single platelets. Virtually all of the platelets were aggregated by thrombin in the absence of the Fab.

Control experiments were done to establish the specificity of the inhibition produced by the antifibrinogen Fab. Nonimmune goat Fab fragments had no effect on aggregation at protein concentrations greater than that required to produce complete inhibition by the antifibrinogen Fab. Similarly, antihuman albumin Fab from rabbits had no effect (Fig. 8C). Thus, it appears that fibrinogen is involved in thrombin-induced aggregation of washed platelets.

ADP did not aggregate washed platelets prepared as described above. When platelets were washed according to the procedure of Ardlie and Han and suspended in modified Tyrode's buffer (17), aggregation was obtained with $1 \mu \mathrm{M} \mathrm{ADP}$, but only after the addition of purified human fibrinogen at a final concentration of

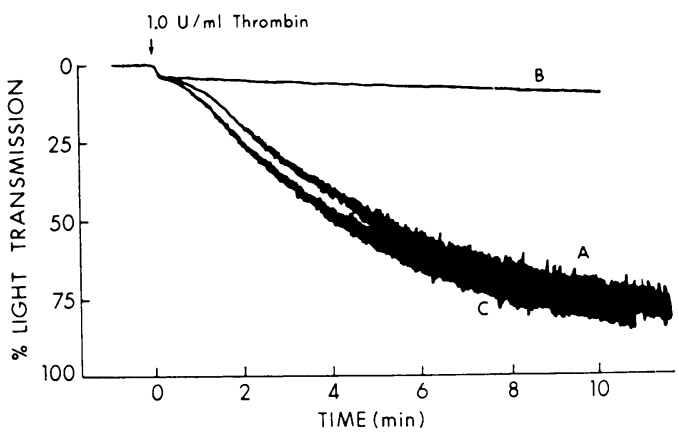

Figure 8 Effect of antifibrinogen Fab on platelet aggregation. Aggregation was measured photometrically as described in Methods. Addition of thrombin (final concentration $1.0 \mathrm{U} / \mathrm{ml}$ ) at the arrow was preceded by a $5-\mathrm{min}$ incubation with the Fab fragments. A, no Fab added. B, $100 \mu \mathrm{g} / \mathrm{ml}$ antifibrinogen Fab. C, $100 \mu \mathrm{g} / \mathrm{ml}$ an ihuman albumin Fab. 
$0.2 \mathrm{mg} / \mathrm{ml}$. Antifibrinogen Fab $(0.2 \mathrm{mg} / \mathrm{ml})$ completely inhibited aggregation induced by ADP under these conditions. The requirement for exogenous fibrinogen in ADP-induced aggregation has been characterized by others (21-23). Since ADP does not cause the release of fibrinogen from platelets (1), the antifibrinogen $F a b$ presumably inhibited aggregation by binding to the exogenous fibrinogen molecules. In contrast, exogenous fibrinogen is not required for thrombin-induced aggregation, and inhibition of thrombin-induced aggregation by antifibrinogen Fab fragments must be due to interaction of the $\mathrm{Fab}$ with endogenous platelet fibrinogen.

Although fibrinogen appears necessary for aggregation of platelets by thrombin or ADP, it is not required for passive agglutination of platelets. For example, Ephytohemagglutinin from kidney beans caused agglutination of platelets (9); however, exogenous fibrinogen was not required for this reaction in washed platelets, and antifibrinogen Fab did not block this agglutination reaction (data not shown).

Platelet aggregation after preincubation with antifibrinogen Fab. The above experiments suggested that fibrinogen is required for platelet aggregation but did not distinguish whether the effect of antifibrinogen Fab was on surface fibrinogen or on fibrinogen released from platelet granules. The following experiment was carried out to distinguish between these two possibilities. Platelets $\left(5 \times 10^{9}\right.$ in $10 \mathrm{ml}$ of isotonic Tris-saline) were incubated for $10 \mathrm{~min}$ at room temperature with $1 \mathrm{mg}$ of antifibrinogen Fab. The platelets were then centrifuged at $2,250 \mathrm{~g}$ for $15 \mathrm{~min}$ to remove unbound Fab fragments, resuspended in isotonic Tris-saline, and used in the aggregation experiment described in Fig. 9. There was no apparent difference in thrombin-in-

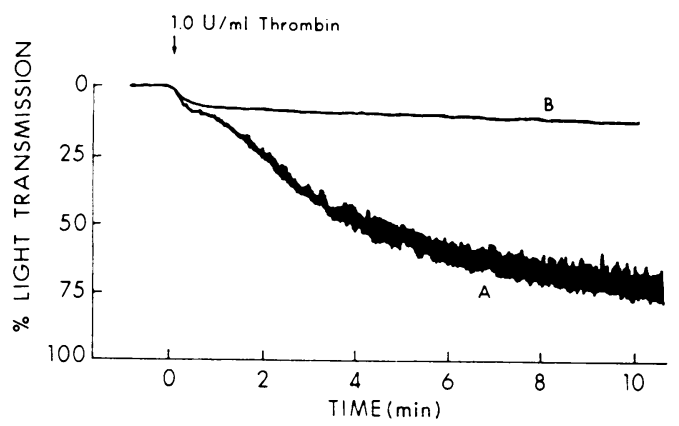

FIgUre 9 Effect of preincubation of platelets with antifibrinogen Fab on platelet aggregation. Platelets were incubated with $\mathrm{Fab}$ fragments and washed once as described in the text, and they were then resuspended at a concentration of $5 \times 10^{8}$ platelets $/ \mathrm{ml}$ in isotonic Tris-saline $(\mathrm{pH} 7.5)$ contained glucose $(1 \mathrm{mg} / \mathrm{ml})$ and $2 \mathrm{mM}$ calcium chloride. Thrombin (final concentration $1.0 \mathrm{U} / \mathrm{ml}$ ) was added at the arrow. A, preincubated and washed platelets. B, preincubated and washed platelets $+100 \mu \mathrm{g} / \mathrm{ml}$ antifibrinogen Fab added $5 \mathrm{~min}$ before thrombin.
TABLE I

Effect of Antifibrinogen Fab Fragments on the Clotting Time of Human Fibrinogen

\begin{tabular}{lcc}
\hline \multicolumn{1}{c}{ Addition } & Clotting time \\
\hline & $\mu \mathrm{g} / \mathrm{ml}$ & $s$ \\
None & & 16.4 \\
Antifibrinogen Fab & 100 & 25.0 \\
Antifibrinogen Fab & 200 & 42.6 \\
Antifibrinogen Fab & 400 & $>120$ \\
Nonimmune Fab & 400 & 16.8 \\
\hline
\end{tabular}

Reaction mixtures contained $150 \mu \mathrm{g} / \mathrm{ml}$ of purified human fibrinogen (21), $0.02 \mathrm{M} \mathrm{CaCl}_{2}$, and the Fab fragments in $0.5 \mathrm{ml}$ of $0.154 \mathrm{M} \mathrm{NaCl}, 0.01 \mathrm{M}$ imidazole $-\mathrm{HCl}(\mathrm{pH} 7.0$ ). After a 5 -min preincubation, thrombin was added at a final concentration of $1 \mathrm{U} / \mathrm{ml}$ to initiate the clotting reaction. Incubations were conducted at room temperature.

duced aggregation between the platelets preincubated with antifibrinogen Fab (Fig. 9A) and control platelets centrifuged and resuspended in the same manner, although addition of the original concentration of antifibrinogen Fab $(100 \mu \mathrm{g} / \mathrm{ml})$ to control or preincubated platelets (Fig. 9B) caused $90 \%$ inhibition of aggregation. From additional experiments using ${ }^{125} \mathrm{I}$-antifibrinogen Fab, we determined that less than $10 \%$ of the bound Fab was removed during the washing procedure. In addition, virtually all of the remaining $F a b$ was still bound to the platelets after thrombin treatment. These experiments indicate that excess antifibrinogen Fab must be present at the time of release to block aggregation, suggesting that released fibrinogen is required for aggregation.

Effect of antifibrinogen Fab on fibrinogen clotting and fibrinopeptide relcase. We studied the effect of the antifibrinogen $\mathrm{Fab}$ on clotting of fibrinogen by thrombin to determine how the Fab might affect the functional properties of fibrinogen. Antifibrinogen Fab fragments prolonged the clotting time of human fibrinogen exposed to thrombin, while Fab fragments prepared from nonimmune goat IgG had no effect (Table I). The prolongation of clotting time could have resulted either from interference with the proteolytic conversion of fibrinogen to fibrin monomers (resulting in the release of fibrinopeptides A and B) or from interference with the polymerization of fibrin monomers to form a visible clot. As shown in Fig. 10, the kinetics of fibrinopeptide release were identical in incubations with or without the antifibrinogen Fab. Since the peptides were quantitated with fluorescamine, a reagent that reacts with primary amino groups (30), only fibrinopeptide A was detected in this experiment. Since others have found that removal of fibrinopeptide $A$ alone is sufficient to cause clotting (38), we infer that the anti- 


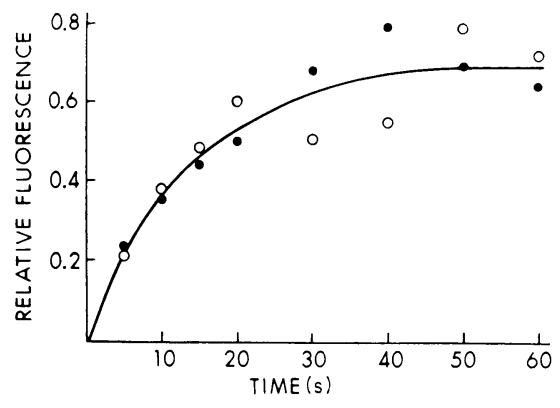

Figure 10 Effect of antifibrinogen Fab fragments on the release of fibrinopeptide A from human fibrinogen. Incubations containing $150 \mu \mathrm{g} / \mathrm{ml}$ of fibrinogen and $1 \mathrm{U} / \mathrm{ml}$ of thrombin were conducted as in the experiment in Table I. Reactions were terminated by the addition of TCA, and the soluble peptides were detected with fluorescamine (see Methods). (๑), no Fab added (clotting time $17 \mathrm{~s}$ ). ( $\mathrm{O})$, $400 \mu \mathrm{g} / \mathrm{ml}$ antifibrinogen $\mathrm{Fab}$ added (clotting time $>2$ $\min )$.

fibrinogen $\mathrm{Fab}$ inhibits clotting by interfering with the polymerization of fibrin monomers rather than by inhibiting proteolysis of fibrinogen by thrombin.

\section{DISCUSSION}

Platelet fibrinogen appears to be directly involved in the thrombin-induced aggregation of human platelets in vitro. This conclusion is based on the observation that monovalent Fab fragments prepared from purified antihuman fibrinogen antibodies inhibit aggregation of washed platelets in response to thrombin, while nonimmune or antihuman albumin Fab fragments do not have an inhibitory effect (Fig. 8). Measurement of the kinetics of $\left[{ }^{14} \mathrm{C}\right]$ serotonin release (Figs. 6 and 7 ) indicate that the release reaction is unaffected by the presence of the antifibrinogen Fab. Thus, the inhibitory effect of the Fab on aggregation is not secondary to inhibition of the release reaction.

Haslam has proposed that thrombin-induced aggregation depends on the release of ADP from the platelets, since an enzyme system capable of removing ADP from the incubation medium inhibits aggregation (39). It is well established that ADP and serotonin are released together from platelets under a variety of stimuli (1), and we can assume, therefore, that ADP release is not affected by the antifibrinogen Fab. It follows that released ADP cannot be the sole mediator of thrombin-induced aggregation.

Platelet fibrinogen comprises about $10 \%$ of the total protein content of platelets (33). It cross-reacts immunologically with plasma fibrinogen, and although there is disagreement as to the structural identity of platelet and plasma fibrinogens $(12,40)$, recent evidence would suggest that they are probably structurally identical (40). Fibrinogen can be detected both on the surface of intact platelets (Fig. 4) and in platelet granules (33) from which the fibrinogen is released along with other granular constituents during the release reaction induced by thrombin (1). When platelets are preincubated with antifibrinogen $\mathrm{Fab}$ at a level sufficient to saturate the surface fibrinogen molecules and are then washed once to remove unbound Fab, we observe no inhibition of aggregation induced by subsequently added thrombin (Fig. 9). This finding suggests that the Fab inhibits aggregation by binding to the fibrinogen released from platelets and that surface fibrinogen is unable to sustain aggregation of washed platelets.

We have shown that the antifibrinogen Fab preparation used in these experiments inhibits the clotting of fibrinogen by thrombin (Table I), and since the rate of proteolytic cleavage of fibrinogen to release fibrinopeptide $\mathrm{A}$ is unaffected by the Fab (Fig. 10), we infer that the Fab binds to fibrin monomers and interferes with their polymerization. The antifibrinogen Fab could thus inhibit platelet aggregation by inhibiting the polymerization of fibrin monomers generated from platelet fibrinogen. This suggestion should be regarded as tentative, however, until it can be shown that fibrin monomers are actually formed during aggregation. Alternatively, the Fab might prevent some function of the intact fibrinogen molecule, such as polymerization with itself or with fibrin monomers, which is essential for aggregation of the platelets. A role for fibrin monomer polymerization has been suggested also by Ardlie and Han (17) and by Niewiarowski, Regoeczi, Stewart, Senyi, and Mustard (16). These investigators have reported that under certain conditions the addition of polymerizing fibrin to platelets causes aggregation, although various other cells, including leukocytes and fibroblasts, are also clumped under similar conditions (41).

A small fraction of platelet fibrinogen is located on the platelet surface (see Results and Fig. 4), where it might take part in the initial interaction of thrombin with platelets. Antifibrinogen Fab fragments at a level sufficient to saturate the surface fibrinogen molecules have no effect on $\left[{ }^{14} \mathrm{C}\right]$ serotonin release (Figs. 6 and 7) and only slightly inhibit "low affinity" binding of ${ }^{125}$ I-thrombin (Fig. 5). These results suggest that surface fibrinogen is not the thrombin receptor for the release reaction. However, it is apparent that the Fab fragments do not bind to certain sites on the fibrinogen molecule, including the site at which thrombin cleaves fibrinogen to release fibrinopeptide $\mathrm{A}$, and therefore the above results do not unequivocally exclude possible involvement of fibrinogen as a thrombin substrate important in inducing the release reaction or as a receptor for thrombin binding. Other independent evidence also suggests that fibrinogen is not the thrombin 
substrate in induction of release, since several snake venoms that coagulate fibrinogen or that release fibrinopeptide $\mathrm{A}$ or $\mathrm{B}$, or combinations of these venoms, do not induce the release reaction in platelets $(11,18,19)$.

In summary, our data suggest a direct involvement of released platelet fibrinogen in thrombin-induced aggregation of human platelets and are consistent with a model for platelet aggregation wherein polymerization of fibrin monomers serves to crosslink platelets into an aggregated mass. Thus "released" fibrinogen may be converted to fibrin monomers both in solution and on the platelet surface, and these monomers may then polymerize to form an aggregate. Whether the surface fibrinogen detected on resting platelets could participate in this process remains uncertain. These conclusions pertain only to the aggregation of washed platelets studied by the usual in vitro technique, which depends critically on temperature, stirring conditions, and other physical parameters. Certain clinical studies, however, suggest that platelet fibrinogen might also have an important function in vivo. For example, in a patient with Glanzmann's thrombasthenia who had a prolonged bleeding time, Zucker, Pert, and Hilgartner found reduced platelet fibrinogen even though the plasma fibrinogen level was normal (42). This patient's platelets underwent a normal release reaction in vitro but did not aggregate in response to thrombin or other aggregating agents and thus resembled normal platelets inhibited, in our experiments, by antifibrinogen Fab fragments.

\section{ACKNOWLEDGMENTS}

We thank Dr. Heinz Joist for his assistance with the experiments using the platelet aggregometer and Dr. Laurence Sherman for assistance with the electrophoresis of fibrinopeptide A. We also thank Mr. Walter Gray for performing the immunoelectrophoresis.

This research was supported by grants HL 16634 and HL 14147 from the National Institutes of Health and by grant PRA 33 from the American Cancer Society.

\section{REFERENCES}

1. Holmsen, H., H. J. Day, and H. Stormorken. 1969. The blood platelet release reaction. Scand. J. Hacmatol. Suppl. 8: 1-26.

2. White, J. G. 1971. Platelet morphology. In The Circulating Platelet. S. A. Johnson, editor. Academic Press, Inc., New York. 45-121.

3. Marcus, A. J. 1969. Platelet function. N. Engl. J. Med. 280: 1213-1220, 1278-1284, 1330-1335.

4. Tollefsen, D. M., J. R. Feagler, and P. W. Majerus. 1974. The binding of thrombin to the surface of human platelets. J. Biol. Chem. 249: 2646-2651.

5. Brodie, G. N., N. L. Baenziger, L. R. Chase, and P. W. Majerus. 1972. The effects of thrombin on adenyl cyclase activity and a membrane protein from human platelets. J. Clin. Invest. 51: 81-88.

6. Lyons, R. M., and P. W. Majerus. 1974. The effect of thrombin on protein phosphorylation in human platelets. J. Clin. Invest. 53: 181a. (Abstr.)
7. Wolfe, S. M., and N. R. Shulman. 1970. Inhibition of platelet energy production and release reaction by $\mathrm{PGE}_{1}$, theophylline and cAMP. Biochem. Biophys. Res. Commun. $41: 128-134$.

8. Phillips, D. R., and P. P. Agin. 1973. Thrombin-induced alterations in the surface structure of the human platelet plasma membrane. Ser. Hacmatol. 6: 292-310.

9. Majerus, P. W., and G. N. Brodie. 1972. The binding of phytohemagglutinins to human platelet plasma membranes. J. Biol. Chem. 247 : 4253-4257.

10. Feagler, J. R., T. W. Tillack, D. D. Chaplin, and P. W. Majerus. 1974. The effects of thrombin on phytohemagglutinin receptor sites in human platelets. J. Cell Biol. 60: 541-553.

11. Davey, M. G., and E. F. Lüscher. 1967. Actions of thrombin and other coagulant and proteolytic enzymes on blood platelets. Nature (Lond.). 216: 857-858.

12. Ganguly, P. 1972. Isolation and some properties of fibrinogen from human blood platelets. J. Biol. Chem. 247 : 1809-1816.

13. Kisselbach, T. H., and R. H. Wagner. 1966. Fibrinstabilizing factor: a thrombin-labile platelet protein. Am. J. Phy'siol. 211: 1472-1476.

14. Cohen, I., I. Bohak, A. DeVries, and E. Katchalski. 1969. Thrombosthenin M. Purification and interaction with thrombin. Eur. J. Biochcm. 10: 388-394.

15. Morse, E. E., D. P. Jackson, and C. L. Conley. 1965. Role of platelet fibrinogen in the reactions of platelets to thrombin. J. Clin. Invest. 44: 809-816.

16. Niewiarowski, S., E. Regoeczi, G. J. Stewart, A. F Senyi, and J. F. Mustard. 1972. Platelet interaction with polymerizing fibrin. J. Clin. Invest. 51: 685-700.

17. Ardlie, N. G., and P. Han. 1974. Enzymatic basis for platelet aggregation and release: the significance of the 'platelet atmosphere' and the relationship between platelet function and blood coagulation. Br. J. Hacmatol. 26: 331-356.

18. Tangen, O., O. K. Wik, and H. J. Berman. 1973. The effect of thrombin, reptilase, and a fibrinopeptide Breleasing enzyme from the venom of the southern copperhead snake on rabbit platelets. Microwasc. Res. 6: 342-346.

19. Brown, C. H., III, W. R. Bell, D. P. Shreiner, and D. P. Jackson. 1972. Effects of arvin on blood platelets. In vitro and in vivo studies. J. Lab. Clin. Mcd. 79: 758769.

20. Gugler, E., and E. F. Lüscher. 1965. Platelet function in congenital afibrinogenemia. Thromb. Diath. Hacmorrh. 14 : 361-373.

21. Cross, M. J. 1964. Effect of fibrinogen on the aggregation of platelets by adenosine diphosphate. Thromb. Diath. Hacmorrh. 12: 524-527.

22. Brinkhous, K. M., M. S. Read, and R. G. Mason. 1965. Plasma thrombocyte-agglutinating activity and fibrinogen. Synergism with adenosine diphosphate. Lab. Invest. 14: 335-342.

23. Solum, N. O., and H. Stormorken. 1965. Influence of fibrinogen on the aggregation of washed human blood platelets induced by adenosine diphosphate, thrombin, collagen, and adrenaline. Scand. J. Clin. Lab. Invest. 17 (Suppl. 84) : 170-182.

24. Straughn, W., and R. H. Wagner. 1966. A simple method for preparing fibrinogen. Thromb. Diath. Hacmorrh. 16: 198-206.

25. Blombäck, B., and M. Blombäck. 1956. Purification of human and bovine fibrinogen. Ark. Kcmi. 10: 415-443. 
26. Cuatrecasas, P. 1970. Protein purification by affinity chromatography. Derivatizations of agarose and polyacrylamide beads. J. Biol. Chem. 245: 3059-3065.

27. Kabat, E. A., and M. M. Mayer. 1961. Experimental Immunochemistry. Charles C. Thomas, Publisher, Springfield, Ill. 22-96.

28. Tollefsen, D. M., J. R. Feagler, and P. W. Majerus 1974. Induction of the platelet release reaction by phytohemagglutinin. J. Clin. Invest. 53: 211-218.

29. Born, G. V. R. 1962. Aggregation of blood platelets by adenosine diphosphate and its reversal. Nature (Lond.). 194: 927-929.

30. Weigele, M., S. L. DeBernardo, J. P. Tengi, and W. Leimgruber. 1972. A novel reagent for the fluorometric assay of primary amines. J. Am. Chem. Soc. 94: 59275928.

31. Herzig, R. H., O. D. Ratnoff, and J. R. Shainoff. 1970. Studies on a procoagulant fraction of southern copperhead snake venom: the preferential release of fibrinopeptide B. J. Lab. Clin. Med. 76: 451-465.

32. Shainoff, J. R., and I. H. Page. 1960. Cofibrins and fibrin intermediates as indicators of thrombin activity in vivo. Circ. Res. 8: 1013-1022.

33. Nachman, R. L., A. J. Marcus, and D. Zucker-Franklin. 1967. Immunologic studies of proteins associated with subcellular fractions of normal human platelets. J. Lab. Clin. Med. 69: 651-658.

34. Lange, R. F., N. R. Shulman, P. A. Tomasulo, and C. N. Coleman. 1973. Metabolic effects of antibodies on platelets. Trans. Assoc. Am. Physicians Phila. 86: 131-142.

35. Andrews, P. 1964. Estimation of the molecular weights of proteins by Sephadex gel-filtration. Biochem. J. 91: 222-233.

36. Steck, T. L., and D. F. H. Wallach. 1965. The binding of kidney-bean phytohemagglutinin by Ehrlich ascites carcinoma. Biochim. Biophys. Acta. 97: 510-522.

37. Born, G. V. R., and M. Hume. 1967. Effects of the numbers and sizes of platelet aggregates on the optical density of plasma. Nature (Lond.). 215: 1027-1029.

38. Blombäck, B. 1958. Studies on fibrinogen: its purification and conversion into fibrin. Acta Physiol. Scand. Suppl. 148: 1-51.

39. Haslam, R. J. 1964. Role of adenosine diphosphate in the aggregation of human blood-platelets by thrombin and by fatty acids. Nature (Lond.). 202: 765-768.

40. Doolittle, R. F., T. Takagi, and B. A. Cottrell. 1974. Platelet and plasma fibrinogens are identical gene products. Science (Wash. D. C.). 185: 368-370.

41. Niewiarowski, S., E. Regoeczi, and J. F. Mustard. 1972. Platelet interaction with fibrinogen and fibrin: comparison of the interaction of platelets with that of fibroblasts, leukocytes, and erythrocytes. Ann. N. Y. Acad. Sci. 201: 72-83.

42. Zucker, M. B., J. H. Pert, and M. W. Hilgartner. 1966. Platelet function in a patient with thrombasthenia. Blood. 28: 524-534. 